\title{
PATIENTS' PERCEPTIONS OF PAIN AND DISCOMFORT DURING DIGITAL RECTAL EXAM FOR PROSTATE CANCER SCREENING
}

\author{
Frederico Ramalho Romero 1,2,3, Antônio Wilson Romero², Thadeu Brenny Filho3, Nageib \\ Mamedio Bark1,3, David Shinobu Yamazaki' y Fernando César de Oliveira Júnior?. \\ I'Instituto Curitiba de Saúde (ICS). Curitiba. PR \\ 2 Hospital Policlínica Cascavel. Cascavel. PR \\ ${ }^{3}$ Hospital São Vicente de Curitiba. Curitiba. PR. Brazil
}

Summary.- OBJECTIVE: To evaluate patients' perception of pain and discomfort during DRE, the impact of discomfort on potential future screening compliance, and if emptying the bladder immediately before DRE reduces patient discomfort.

METHODS: One-hundred patients undergoing DRE for prostate cancer screening answered an anonymous questionnaire regarding pain, urinary urgency and bowel urgency during DRE and its potential impact on future examination. Another group with 100 patients was randomized in two subgroups to analyze if urinating immediately before DRE reduces patient discomfort.
Frederico Ramalho Romero Rua Emiliano Perneta, 653 ap 41 80420-080 Curitiba. Paraná. (Brazil) frederico.romero@gmail.com Accepted for publication: $9^{\text {th }}$ August, 2007.
RESULTS: Seventy-three (73\%) patients reported moderate or higher discomfort for at least one of the domains evaluated: $61 \%$ complained of pain; $22 \%$ of urinary urgency; and $22 \%$ of bowel urgency. Emptying the bladder immediately before examination did not reduce pain $158 \%$ vs. $50 \%, p=0.115)$, urinary urgency $122 \%$ vs. $16 \%, p=0.1511$, or bowel urgency intensity $116 \%$ vs. $14 \%, p=0.264)$. There was no difference in the number of patients that answered they will repeat the prostate exam next year $196 \%$ vs. $90 \%, p=0.2111$ or in those that would encourage a friend that needs the prostate exam to do it $196 \%$ vs. $98 \%, p=0.378)$.

CONCLUSIONS: Pain and discomfort during DRE are not negligible but they do not affect intention to have a prostate exam in the future. Urinating immediately before examination does not significantly reduce the incidence of pain, urinary urgency, or bowel urgency during DRE.

Keywords: Prostate cancer. Screening. Pain.

Resumen.- OBJETIVO: Evaluar la percepción por los pacientes de dolor y molestia durante el tacto rectal, el impacto de la molestias sobre el potencial futuro cumplimiento con el "screening", y si el vaciado vesical inmediatamente anterior al tacto rectal disminuye la molestias.

MÉTODOS: 101 pacientes sometidos a tacto rectal por detección precoz de cáncer de próstata contestaron un cuestionario anónimo sobre dolor, urgencia urinaria y urgencia fecal durante el tacto rectal y su potencial impacto sobre futuros exámenes. Otro grupo de 100 pacientes fue asignado aleatoriamente a dos subgrupos 
para analizar si la micción inmediatamente anterior al tacto rectal reduce la molestia.

RESULTADOS: Setenta y tres (73\%) de los pacientes comunicaron una molestia moderada o superior en al menos uno de los dominios evaluados: el $61 \%$ se quejaron de dolor; el $22 \%$ de urgencia miccional; y el $22 \%$ de urgencia fecal. El vaciado de la vejiga inmediatamente antes del examen no redujo el dolor $158 \%$ vs. 50\%, p $=0,115)$, ni la urgencia urinaria $(22 \%$ vs. $16 \%, p=$ 0,1511 ni la intensidad de la urgencia fecal $116 \%$ vs. $14 \%, p=0,264)$. No hubo diferencias en el número de pacientes que contestaron que repetirían el examen al siguiente año (96\% vs. 90\%, $p=0,211)$ o en el de aquellos que animarían a hacérselo a un amigo que necesitara una evaluación prostática $196 \%$ vs. 98\%, p $=0,378$.

CONCLUSIONES: El dolor y la molestia durante el tacto rectal no son despreciables aunque no afectan a la intención de repetir el examen en el futuro. Orinar inmediatamente antes de la exploración no reduce significativamente la incidencia de dolor, urgencia urinaria o urgencia fecal durante el tacto rectal.

Palabras clave: Cáncer de próstata. Detección precoz. Cribado. Dolor.

\section{INTRODUCTION}

Prostate cancer is the most common form of noncutaneous cancer in men and the second leading cause of male cancer mortality. In the United States, it is estimated that 218,890 new cases and 27,050 deaths from prostate cancer will occur in 2007 (1). It is widely recognized that digital rectal examination (DRE) is an important tool that should be routinely performed when screening for prostate cancer. Compared to the large amount of prostate cancer screening literature, very little has been written about patient pain or discomfort during DRE. Although several patient information guides report DRE causes no pain (2-4) or a slight discomfort $(5,6)$ it has been reported physicians tend to give lower ratings of patients' pain than do the patients themselves (7). To our knowledge there are no studies specifically addressing patients' perception of pain or discomfort during DRE.

Anticipated pain or discomfort is an important barrier to prostate cancer screening (8), and it may impair future examination compliance (9-11). To help in patient information and counseling for prostate cancer screening we performed a study to evaluate patients' perception of pain and discomfort during DRE. We also evaluated the impact of discomfort on potential future screening compliance, and if emptying the bladder immediately before DRE reduces patient discomfort.

\section{MATERIALS AND METHODS}

\section{Patient Selection}

During a prostate cancer screening program at our Institution, 200 patients completed a questionnaire regarding pain and discomfort during DRE and its potential impact on future examination.

In the first part of the study, 100 patients voluntarily undergoing prostate cancer screening were included. Illiterate patients, those who did not consent with the study, and patients with clinical or laboratory evidence of urinary tract infection or prostatitis were excluded.

In a second part, 100 patients were randomly divided in two subgroups to analyze if emptying the bladder - or not - immediately before DRE reduces patient discomfort. Fifty patients were asked to urinate immediately before examination (intervention group) and 50 patients underwent DRE without urinating (control group). Patients were matched by age (between 50 and 59 years), level of education (complete elementary school or higher), AUA prostate symptom score (less than or equal to 7 ), and prostate specific antigen (PSA) value (below $4.0 \mathrm{ng} / \mathrm{dL}$ ). Patients with current history of pain or bleeding with bowel movements, prior history of anal surgery, and those with DRE suspicious for cancer were excluded from this part of the study. Randomization was stratified according to the day of the week DRE was performed. Patients were asked to urinate before examination if they were examined on Mondays, Wednesdays, and Fridays. Patients undergoing DRE on Tuesdays and Thursdays underwent examination without urinating. DRE was performed in all patients by the same investigator (FRR) in the modified lithotomy position with the use of topical lidocaine $2 \%$ gel.

\section{Questionnaire}

Immediately after examination, each patient responded a self-administered anonymous questionnaire containing 5 questions. The first three questions regarded patient discomfort related to pain, urinary urgency, and bowel urgency. Impact of discomfort on potential future screening compliance was evaluated with questions 4 and 5 (Table I).

\section{Statistical analyses}

To evaluate discomfort improvement with micturition immediately before DRE, discomfort grade was expressed as categorical variables (absent/mild 
vs. moderate/severe/unbearable) in the two subgroups of the study. Impact of discomfort on potential future screening compliance was also expressed as categorical variables (yes vs. no).

Categorical data was analyzed using Fisher or Chi Square tests. Continuous data were evaluated using the Mann-Whitney $U$ test. Statistical significance was considered for values $p<0.05$.

\section{RESULTS}

For the first part of the study median age was 50 years (range $40-66$ ). Seventeen (17\%) patients had incomplete elementary school education and 73 $(73 \%)$ patients had a complete elementary school or higher education. Median AUA prostate symptom score was $3 \pm 4$ (range 0 to 19). Median PSA level was $0.79 \pm 1.02 \mathrm{ng} / \mathrm{dL}$ (range 0.17 to 8.55 ).

1. How much pain did you experience during the prostate exam?

1. Absent - 05

2. Mild - 34

3. Moderate - 41

4. Severe - 17

5. Unbearable - 03

2. How much urge to urinate did you experience during the prostate exam?

1. Absent - 36

2. Mild - 42

3. Moderate - 17

4. Severe - 05

5. Unbearable - 00

3. How much urge to defecate did you experience during the prostate exam?

1. Absent -48

2. Mild - 30

3. Moderate - 16

4. Severe - 04

5. Unbearable - 02

4. Will you repeat the prostate exam next year?

1. Yes-94

2. No- 06

5. Would you encourage a friend that needs the prostate exam to do it?

1. Yes - 95

2. No- 05 
Discomfort grade related to pain, urinary urgency and bowel urgency is summarized in Table I. Seventy-three $(73 \%)$ patients reported moderate, severe or unbearable discomfort for at least one domain during DRE: $61 \%$ complained of pain; $22 \%$ of urinary urgency; and $22 \%$ of bowel urgency. Ninety-four $(94 \%)$ patients answered they will repeat the prostate exam next year and 95 (95\%) would encourage a friend that needs the prostate exam to do it.

For the second part of the study median age was 52 years (range 50 - 59) for the group of patients that was asked to urinate immediately before DRE (intervention group) and 52 years (range 50 - 59) for the control group ( $p=0.684$ ). Median AUA prostate symptom score was $2 \pm 2$ (range 0 to 7 ) in intervention group and $2 \pm 2$ (range 0 to 7 ) in the control group ( $p=0.975$ ). Median PSA level was $0.74 \pm 0.45 \mathrm{ng} / \mathrm{dL}$ (range 0.03 to 1.98 ) and $0.77 \pm$ 0.75 (range 0.17 to 3.71 ) in intervention and control groups respectively $(p=0.352)$.

Emptying the bladder immediately before examination did not reduce the incidence of moderate, severe or unbearable pain $(58 \%$ vs. $50 \%, p=$ $0.115)$, urinary urgency $(22 \%$ vs. $16 \%, p=0.151)$, or bowel urgency $(16 \%$ vs. $14 \%, p=0.264)$. There was no difference in the number of patients that answered they will repeat the prostate exam next year $(96 \%$ vs. $90 \%, p=0.162)$ or in those that would encourage a friend that needs the prostate exam to do it $(96 \%$ vs. $98 \%, p=0.378)$.

\section{DISCUSSION}

Digital rectal exam is an important tool used for diagnosis and clinical staging of prostate cancer. It was used as the only method for the detection of prostate cancer for many years. Even after the introduction of PSA for clinical use in 1985 - 1986 evidences suggest that combining PSA and DRE improves the overall rate of prostate cancer detection when compared with either test alone (12-14).

Anticipated pain or discomfort is one of the main barriers to prostate cancer screening (8). In this study, we found that $73 \%$ of the patients complained of moderate or higher discomfort for at least one of the domains evaluated during DRE.

Several medical conditions may produce pain or discomfort during DRE including anal fissure, abscess and fistula, prostatitis and prostatic abscess. In the absence of organic disease, pain may result from anal sphincter contraction and palpation of the prostate, seminal vesicles and bladder trigone. All these structures are innervated by afferent branches of the visceral nervous system, which transmit sensations of pain by branches of both the parasympathetic and sympathetic divisions of the autonomic nervous system.

Sociodemographic factors - age, race, level of education and income - may alter pain/discomfort perception $(7,9,10,15)$. Patients' beliefs, anxiety and attitudes may also account on patient discomfort $(7,10,11,15)$. They may feel embarrassed about undressing, worried about cleanliness, and fear discovering a pathological condition. Lack of information about the procedure and lack of empathy and gentleness from the examiner are also perceived as important factors $(7,10,15)$. A sense of vulnerability and defenselessness associated with patient positioning may interfere with physical and psychological distress associated with the examination (11).

Physical and psychological trauma experienced during screening may result in decreased compliance with future screening (9-11). Negative experiences reported by friends may also influence screening compliance (9). In our study, most patients responded they will repeat the prostate exam the following year. They also answered they would encourage a friend that needs the prostate exam to do it, and these responses were not different regardless of the discomfort level experienced during DRE. Even though patients responded positively regarding potential future screening compliance, suggesting that they understand the gravity of regular examinations, intention to undergo screening does not necessarily reflect actual screening compliance.

Reduction in physical stress during DRE is expected to improve patient satisfaction and compliance. Previous information about the procedure, examination in a warm and reserved exam room with a toilet, positioning the patient in the modified lithotomy position which allows direct eye contact of the patient with the examiner, and explaining the findings to the patient during the examination may all help reduce the patients' physical and psychological distress.

In this study, emptying the bladder immediately before DRE resulted in a decrease from $22 \%$ to $16 \%$ in moderate to unbearable urinary urgency. This result however did not reach statistical significance. Although this may be explained because of the relatively small number of patients in each group, alternative explanations must be considered. The volume of urine in the patients that did not urinate before DRE (control group) was not evaluated. Some patients may have urinated before entering the medical office. Additionally, we did not assess residual urine volu- 
me in patients that urinated before DRE (intervention group). Finally, urinary urgency may have resulted from touching the prostate and bladder trigone independently of the amount of urine in the bladder. These issues should be specifically addressed in future studies. We would argue however that if our results are confirmed physicians and primary care providers may save time by skipping the pre-DRE void.

Although the questionnaire used in this study was not validated, the scale used in this study is well established and has been extensively used in clinical research for evaluation of pain and discomfort.

Our study shows that patients may feel significant discomfort with DRE even in the absence of organic disease, justifying the fear of pain reported as an important barrier to prostate cancer screening. 8 Patients should be informed about the probability of feeling temporary pain or discomfort during prostate exam. Measures to decrease patient distress when screening for prostate cancer should be evaluated.

\section{CONCLUSIONS}

Our study challenges the concept that the prostate exam is a painless procedure since less than a third of our patients reported mild or no pain during DRE. Urinary urgency and bowel urgency occur in a smaller percentage of patients. The degree of pain or discomfort does not affect intention to have a prostate exam in the future. Urinating immediately before examination does not significantly reduce the incidence of pain, urinary urgency, or bowel urgency during DRE.

\section{REFERENCES AND RECOMENDED READINGS (*of special interest, ${ }^{* *}$ of outstanding interest)}

1. JEMAL, A.; SIEGEL, R.; WARD, E. y cols.: "Cancer Statistics, 2007”. C.A. Cancer J. Clin., 57: 43, 2007.

2. AMERICAN CANCER SOCIETY, INC: "Detailed guide: Prostate cancer". http://www.cancer. org/docroot/CRI/content/CRI_2_4_3X_Can_prostate_cancer_be_found_early_36.asp

3. JOHNS HOPKINS HEALTH ALERT: "The DRE - Don't skip it". http://www.johnshopkinshealtha-
lerts.com/alerts/prostate_disorders/JohnsHopkinsProstateHealthAlert_209-1.html

4. UNIVERSITY OF MARYLAND SCHOOL OF MEDICINE: "Facts about prostate cancer". http:// medschool.umaryland.edu/minimed/prostatefacts. htm

5. WEBMD, INC: "Prostate cancer: digital rectal examination for prostate problems". http://www. webmd.com/content/article/45/1688_50839.htm

6. HEARTSPRING.NET: "Prostate medical exam". http://www.heartspring.net/prostate_cancer_exam. html

**7. MARQUIE, L.; RAUFASTE, E.; LAUQUE, D. y cols.: "Pain rating by patients and physicians: Evidence of systematic pain miscalibration". Pain, 102: 289, 2003.

**8. NIJS, H.G.; ESSINK-BOT, M.L.; DEKONING, H.J. y cols.: "Why do men refuse or attend population-based screening for prostate cancer?". J. Public. Health. Med., 22: 312, 2000.

*9. FREITAS, R. 2nd.; FIORI, W.F.; RAMOS, F.J. y cols.: "Discomfort and pain during mammography”. Rev. Assoc. Med. Bras., 52: 333, 2006.

*10. KEEMERS-GELS, M.E.; GROENENDIJK, R.P.; VAN DEN HEUVEL, J.H. y cols.: "Pain experienced by women attending breast cancer screening". Breast Cancer Res. Treat., 60: 235, 2000.

**11. SEEHUSEN, D.A.; JOHNSON, D.R.; EARWOOD, J.S. y cols.: "Improving women's experience during speculum examinations at routine gynaecological visits: Randomised clinical trial”. BMJ, 333: 171, 2006.

12. RICHIE, J.P.; CATALONA, W.J.; AHMANN, F.R. y cols.: "Effect of patient age on early detection of prostate cancer with serum prostate-specific antigen and digital rectal examination". Urology, 42: 365, 1993.

*13. BRETTON, P.R.: "Prostate-specific antigen and digital rectal examination in screening for prostate cancer: A community-based study". South Med. J., 87: 720, 1994.

14. MUSCHENHEIM, F.; OMARBASHA,B.; KARDJIAN, P.M. y cols.: "Screening for carcinoma of the prostate with prostate specific antigen". Ann. Clin. Lab. Sci., 21: 371, 1991.

*15. HILDEN, M.; SIDENIUS, K.; LANGHOFFROOS, J. y cols.: "Women's experiences of the gynecologic examination: Factors associated with discomfort". Acta Obstet. Gynecol. Scand., 82: $1030,2003$. 